\title{
LETRAS ENTRE CLIO E PSIQUE: A CRIATIVIDADE E A MITOLOGIZAÇÃO DO PROFANO
}

Aleš Vrbata

Resumo: Criatividade significa um mergulho às camadas profundas da psique com todo legado psíquico, espiritual e religioso nela conservado. Nos tempos modernos a produção literária e intelectual se realiza no mundo profano que já perdeu contato com o significado simbólico dos eventos. Mesmo que o autor talvez tenha acesso ao legado da alma ancestral, ele vive no e produz para o mundo profano. Os autores aqui apresentados foram confrontados com o abismo entre essas duas esferas e optaram pela mitologização do profano ou pela criação da mitologia secularizada civil. Barrès, Drieu, Maurras ou Groulx acessavam o imaginário coletivo e recriavam ou ressuscitavam a alma ancestral através dos projetos (pseudo)profanos.

Palavras chave: Política. Literatura. Mito. Imagem. Decadência. Tradição.

\section{LETTERS BETWEEN CLIO AND PSYCHE: THE CREATIVITY AND MYTHOLOGIZATION OF THE PROFANE}

\begin{abstract}
Being creative means diving deep in the unconscious levels of the psyche with all its psychic, spiritual or religious legacy. In modern times literary and intellectual creativity takes place in profane space which has already lost touch with symbolic meaning of events. Even though the author has an access to the legacy of ancestral soul, he/she lives in and for profane society. Authors such as Barrès, Drieu, Maurras or Groulx were confronted with such a paradox and resolved it by mythologizing the profane. Thus, their works can be considered attempts to mythologize again a modern profane society.
\end{abstract}

Keywords: Politics. Literature. Myth. Image. Decadence. Tradition. 
he experience of reality is a product of the psyche's capacity to image. It is not an external being (god, ideal, or matter), but, rather, the 'essence' of being human. Subjectively, reality is experienced as 'out there', because its originary principle is located 'in the beyond,' transcendent to the ego's subjectivity. With this ontological shift, mental image ceases to be viewed as a copy, or a copy of a copy, and now assumes [...], the role of ultimate origin and creator of meaning and of our sense of existence and reality (KUGLER, 2008, p. 87). ${ }^{1}$

Like the novelist, the historian construct a complete world around him, which must form a coherent whole (COLLINGWOOD, 1994, p. 245). ${ }^{2}$

\section{Imaginal além do fenomenal}

Tradicionalmente, a história fazia parte da literatura e também da mitologia e foi regida pela musa Clio, filha da deusa da memória, Mnemósiné. Os bardos, poetas, cantores foram inspirados pelas musas. $\mathrm{O}$ ato criativo deles requeria inspiração vinda das musas, i.e., inconsciente, um mergulho nas camadas mais profundas da alma. Em outras palavras, o ato criativo foi, inevitavelmente, também um ato profundamente psicológico.

O iluminismo e os processos modernizadores não significavam só a superação das velhas autoridades e das tradições mas, também, a introdução dos novos mitos que poderiam ser rotulados como "secularizantes", "racionalizantes", "progressistas". Consequentemente, a história se emancipou da literatura (em nome da objetividade ou da cientificidade). Mas este processo emancipatório nunca foi devidamente concluído porque o século XIX - pelo menos na Europa - nunca foi completamente positivista, científico, objetivo, industrializado, mecanicizado e universalista e sempre carregou e até desencadeou uma carga considerável do romantismo, do particularismo, da contra-revolução.

Quando o historiador de psiquiatria e autor da obra célebre The Discovery of Unconscious, Henri Ellenberger, caracterizou o romantismo,

\footnotetext{
${ }^{1}$ A experiência da realidade é o produto da capacidade de imaginar da psique. Nao é um ser exterior (deus, ideal ou matéria) mais antes uma "essência" de ser humano. Subjetivamente, a realidade é vivenciada como "lá fora" porque o princípio original dela está 'além', transcende a subjetividade do ego. Com esta mudança ontológica, a imagem mental já nao pode ser vista como cópia ou como cópia da cópia e agora assume [...] o papel da origem final, do criador do sentido e do nosso senso da existência e realidade.

${ }^{2}$ Tanto quanto o escritor, o historiador constrói ao seu redor um mundo completo que deve constituir um conjunto coerente.
} 
ligou-o com o ditame de Schelling "A natureza é espírito visível, espírito é a natureza invisivel" (tese exemplificada na Naturphilosophie dele, talvez antecipando o inconsciente coletivo junguiano) e apresentou as seguintes características do romantismo: 1) a crença na alma mundial (Weltseele), 2) Naturphilosophie ou a crença numa unidade essencial do ser humano e a natureza, 3) Urphänomene (fenômenos primordiais), 4) crença em "metamorphosis" ou "formative change", 5) a nocão do inconsciente (a maneira prelapsariana do primeiro ser humano como conhecer e perceber o mundo), 6) o interesse pelo exótico (distante em termos de tempo ou espaço), i.e., história, arqueologia, paleontologia, geologia, paleografia, ciência das religiões, mitologia comparativa, etc.

O exemplo da abordagem romântica é Sigmund Freud que, tentando escrever Zeitdiagnose do Ocidente da época, não recorreu à ciência no sentido estreito mas ao mito do Édipo, mito do pai primordial. Um pouco mais tarde, Jung recorreu à mitologia universal na sua primeira grande obra, Wandlungen und Symbole der Libido (1912). Jung - diferentemente de Zeitgest do XIX século - começou a defender "Psychologie mit Seele"(psicologia com alma) e, junto com outros autores, revelar que atrás da "realidade" profana espacotemporal há uma dimensao trans-histórica. Em outras palavras, se dizemos que o imaginal precede o fenomenal continuamos na tradição do pensamento romantico. No decorrer do século XX, esta perspectiva se expandiu não somente à psicologia e à psicoterapia mas, também, aos estudos literários, estudos culturais, à mitografia, à história, à história da arte, aos estudos das relações internacionais, à física. A dimensão subjetiva da experiência, tão cara aos românticos, tornou-se um elemento importantíssimo do conhecimento:

The idea that myth connotes a reality runs counter to the mainstream of modern Western thought, beginning with the rationalism of the seventeenth century, which has tended to equate the word „myth“ with „fancy“, meaning fallacy, delusion, or a mistaken notion, that which opposes what can be proven as fact [...]. The founders of psychoanalysis, Sigmund Freud and Carl Jung, thought that another form of discourse was called for to explain human behavior [...]. They turned to myth as a means of expression for this aspect of psychological life - the Oedipal myth for Freud and universal mythology for Jung. With myth as primary tool, the psychoanalysis of human nature was first applied to the individual psyche and was then expanded to group psychology, including 
the analysis of culture and national character (SCHENK, 2012, p. xiii-xiv). ${ }^{3}$

A leitura da psique humana através do mito foi sem dúvida influenciada pelo aspecto psicológico da literatura romântica. Os psicólogos do inconsciente foram bastante inspirados por ela mas, também, os escritores foram inspirados pela psicologia. Carl Gustav Jung se inspirou na obra de E. T. A. Hoffmann Die Elixiere des Teufels onde podemos encontrar exemplificações de todos os arquétipos principais e os conceitos dele. Thomas Mann, por sua vez, foi influenciado tanto por Freud quanto por Jung e o romance dele Der Tod in Venedig ou a trilogia Joseph são marcadas por teorias deles.

Esta corrente intelectual inspirada pelo romantismo surgiu na literatura, na psicologia e nas artes e, já no início do século XX, se expandiu também para as outras áreas (Eranos). Esta perspectiva mostra que "myths, dreams and fantasies problematize existence - that is, they demonstrate just how problematic the attitudes of the ego are" [os mitos, os sonhos e as fantasias problematizam a existência - isto é, demonstram como são problemáticas as atitudes do ego] (ADAMS, 2010, p. 49). No decorrer do século $\mathrm{XX}$, o mito e o sonho, passo a passo tornaram-se não só uma royal way to unconscious, mas, também, ferramentas explicativas da interpretação da cultura, da sociedade, das artes, das políticas. Wilfred R. Bion diferencia entre private myth (aprendizagem através da experiência pessoal) e public myth (aprendizagem através da experiência coletiva). Por exemplo, Bion descreve três mitos (de Édipo, de Esfinge, de Jardim de Eden, de Árvore de Conhecimento, de Torre de Babel) dos quais todos falam da relação entre o ser humano (ego) e deus (inconsciente, o atemporal, o arquetípico; na religião: o céu, o sagrado). O primeiro, o mito de Édipo fala da relação entre os pais e os filhos, o outro, o mito do Jardim de Éden fala sobre a relação entre o bem e o mal, e o último fala sobre a comunicação e a confusão. Esses mitos, por essência, contêm conflitos, mas esses conflitos contêm também um potencial

\footnotetext{
${ }^{3}$ A ideia do mito conota a realidade que vai contra a corrente principal do pensamento moderno ocidental começando pelo racionalismo do século XVII que tinha tendência a igualar a palavra "mito" com a "fantasia", i.e., ficção, ou uma noção errada, aquilo que opõe ao que pode ser provado como fato [...]. Os fundadores da psicanálise Sigmund Freud e Carl Jung pensavam que outra forma do discurso pode explicar o comportamento humano [...]. Eles se dirigiam ao mito como meio de expressão desse aspecto da vida psicológica - o mito de Édipo para Freud, a mitológica universal para Jung. Com o mito como o meio primário, a psicanálise da natureza humana foi aplicada pela primeira vez à psique humana a depois expandiu à psicologia de grupos, inclusive, a análise da cultura e do caráter nacional.
} 
de aprendizagem (i.e., o aumento da consciência ou da conciliação dos opostos).

Nas últimas décadas, o termo collective unconscious foi suplementado por termos como archetypal unconscious, cultural unconscious ou mythological unconscious. Estas expressões são só elaboração das idéias que encontramos em Jung, Marie-Louise von Franz ou em Erich Neumann. O inconsciente é entendido como historicamente estratificado, i.e., o inconsciente de cada indivíduo contém camadas que compartilha com as outras culturas e assim carrega o passado histórico da humanidade. Em outras palavras, há imagens e símbolos intrínsecos só a algumas culturas e aqueles que são universalmente humanas. Enquanto o inconsciente cultural "consists of general, abstract, global forms; [cultural unconscious consists of contentes] that are idiomatic to a specific culture" (ADAMS, 2010, p. 64). Como diz Marie-Louise von Franz: "up until today, I have never analyzed an Italian, man or woman, in whom motifs from classical antiquity did not appear in a fully living condition in dreams" [até agora eu nunca analizei um Italiano, mulher ou homem, em cujos sonhos não apareciam motivos da antiguidade clássica] (ADAMS, 2010, p. 64). Em outras palavras, o inconsciente é, ao mesmo tempo, cultural, arquetípico e mitológico. Nem todos os mitos ou figuras mitológicas são distribuidos proporcionalmente em todas as culturas, mas alguns são. Segundo pesquisadores contemporâneos (WILLIAM G. DOTY, LEWIS HYDE, WILLIAM J. HYNES) (ADAMS, 2010, p. 74) ${ }^{4}$ trickster tem distribuição global, i.e., existe nas mesmas proporções no inconsciente de todas as culturas e pode ser considerado um arquétipo multicultural. Para Hillman "or a predominantly Euro-centric culture, the Greek/Roman patterns are the most relevant and most differentiated, and thus the most powerful" [ou uma cultura predominantemente euro-céntrica, os padrões grego-romans são mais relevantes e mais diferenciados e então mais poderosos] (ADAMS, 2010, p. 75). Adams, que chamou atenção à condição da psique na era do multiculturalismo diz que "multiculturalism presents an opportunity, without historical precedents, to practice comparative mythology - or, from a Jungian perspective, comparative psychology" [multiculturalismo apresenta uma

\footnotetext{
${ }^{4}$ A pesquisa arquetípica é sempre interdisciplinar porque considera a psique não só como condição interior de um ser humano mas também como a expressão exterior dela através das épocas, i.e., literatura, cultura, arquitectura etc.
}

Pontos de Interrogaçầo, v. 7, n. 2, jul.-dez., p. 19-45, 2017. 
oportunidade onde precedentes históricos para praticar a mitologia comparativa - ou, da perspectiva junguiana, a psicologia comparativa] (ADAMS, 2010, p. 75)

Este artigo se dedica aos escritores ou aos intelectuais que "leram" ou "leem" sobre a história, a sociedade e o comportamento humano, tendo em vista o imaginário coletivo ou o inconsciente. Falando sobre "la terre et les morts", Barrès fez saber que a alma ancestral tem aspecto biológico e histórico; também Groulx equiparou a raça e a alma como se manifestaram na língua, nas tradições e na religião; contemporâneo deles, Salazar desejava que o povo dele vivesse habitualmente, i.e., seguindo tradições pré-modernas católicas e esforçou-se para não sucumbir pelo que ele mesmo chamou "o moderno estado monstruoso". O imaginário promovido por ele é perfeitamente visível em "Portugal dos Pequenitos", em "Lição de Salazar" de Martins Barata ou num soneto predileto dele da autoria de Christophe Plontin Bonheur de ce monde; Maurras falava sobre race latine e acreditava que se os povos do Mediterrâneo e os descendentes deles nas Américas voltam para as tradições do classicismo, do catolicismo e da antiquidade, eles irão abandonar a decadência e regenerar-se. Em todos testemunhamos a inspiração pelo imaginário coletivo, que serviu preponderamente como fonte inspiradora, mas também uma visão pessoal, um daimon, que dirigia atuação criadora deles. No pensamento de Barrès, Maurras ou Groulx se trata do imaginário regressivo da sociedade rural e pré-moderna onde as tradicoes ancestrais sao conservadas e assim o povo continua nutrido pela alma ancestral. Não se trata do imaginário do progresso prometeano, do culto do futuro, mas do culto do passado e dos ancestrais. Ainda por cima, a vida (ou a infância) refere-se às experiências traumáticas da ameaça exterior (Barrès, Groulx), crise religosa ou niilista (Maurras). Esses autores foram envolvidos com uma atuação política e com uma ideológica intensa. Todos traduziam, quase imediatamente, as suas fantasias para uma realidade social, tanto através dos romances, das análises políticas, das doutrinas políticas quanto pela atuação política direta. A ideia do passado idealizado e do paraíso perdido está sempre presente do mesmo modo que os traços da infância perturbada. Como diz Mário Jacoby:

\footnotetext{
${ }^{5}$ Enquanto na idade média a alma foi concebida e entendida metafisicamente, a partir do século XVIII a alma começou a ser privatizada, profanizada e secularizada. O surgimento da psicologia no decorrer do século XIX acrescentou outros fatores (por exemplo o conceito de inconsciente). Por isso, no século XIX a alma começou a ser psicologizada, biologizada.
} 
This homesickness or nostalgia is apparently related to something which need not exist in external reality. It is the longing for oneness with the mother in a state of problem-free containment, where total harmony, full accord, utter security and consolation reing supreme. Ultimately, it is a longing for the mother as the "containing world", as experienced in the best of circumstances in the so-called primal relationship, the initial link between mother. The perspective of depth psychology links ideas of Paradise, the Golden Age or the "intact world" with the pre-conscious state of infancy [...] (JACOBY, 2006, p. 7). ${ }^{6}$

\section{A história a partir do imaginal}

No momento quando tocamos o aspecto subjetivo ou psicológico da obra do historiador/intelectual, nós nos encontramos no campo subjetivo onde rege a musa mítica Clio e para onde alguns autores se deslocam fazendo "imaginative leap" ou "trance-portation"(Ruth Meyer). Em outras palavras, o trabalho criativo de um escritor-historiador-intelectual tem a sua dimensão subjetiva, íntima onde se encontram como companheiras Psique e Clio como musas-inspiradoras daquele que cria. A atividade criativa não é puramente fatual e realista, tem o seu lado subjetivo, inspirativo, psicológico e até insconsciente. A atividade criativa é um processo durante a qual a psique consciente entra em contato com as camadas mais profundas do inconsciente ou o que poderiamos chamar de alma ancestral. Este campo é aquele cujo os intelectuais - nomeadamente aqueles que se identificam com a racioanalismo frio e matter-of-fact mentality - nao são sempre conscientes, mas vários intelectuais-historiadores prestigiosos como Arnold Joseph Toynbee, Walter Laqueur, G.M. Trevelyan, A. L. Rowse, R. Cobb, Simon Shama são conscientes dessa realidade à semelhança do poeta como William Wordsworth, psicólogos Erik Erikson, Erich Neumann ou James Hillman. No fim dos anos 50, a ligação entre a dimensão subjetiva psicológico-mitologica do ser humano e aquela objetiva espaço-temporal levou ao surgimento da psicohistória. No ano 1956, Toynbee, declarou:

\footnotetext{
${ }^{6}$ Esta saudade ou nostalgia é aparentemente relacionada a algo que não precisa da realidade externa. Nesta ansiedade pela união com a mãe no estado de contentamento sem problemas onde a harmonia total, o acordo pleno, a segurança total e a consolação regem. E finalmente é a ansiedade pela mãe como "o mundo contentor", como é vivenciado na melhor das circunstâncias no assim chamado relacionamento primário, o laço inicial com a mãe. A perspectiva da psicologia profunda faz conexão entre o Paraíso, a Idade de ouro ou o "mundo indene" e o estado pré-consciente da infância [...].
} 


\begin{abstract}
As an historian, I can speak only for myself, to my mind, Jung has added a new dimension to history by opening up, for historians, an entry through which they can explore the subconscious depths of psyche. And he has, I believe,done more for history than that. The subconscious is a subterranean river from which the springs of all conscious activities draw their waters. The subconscious is thus the avenue to a comprehensive study of human nature and human affairs (TOYNBEE, 1956, p. 193). ${ }^{7}$
\end{abstract}

Já no ano seguinte o presidente da American Historical Association, William Langer, insistiu em next assignment para os historiadores e recomendou a eles estudarem psicologia profunda. Mesmo que colaboração entre historiografia e psicologia profunda foi as vezes descrita como "perigosa" ou "a recipe for disaster", "historians like Hunt, Barzun ou Stannard have addressed why historical thought and depth psychology, which share so much in common ground, have failed to form a successful partnership" (MEYER, 2007, p. 11). ${ }^{8}$ Os historiadores e outros intelectuais ficaram conscientes do fato de que a psique humana não pertence ao ego individual, mas tem várias camadas de coletividades, de comunidades, de religiões e de civilizações. Assim - reconhecendo que a nossa "realidade" está se formando de dentro começaram a entrar no domínio da Mnemosine, deusa da memória, mãe da Clio. Em outras palavras, a historiografia começou a tocar algo que na literatura está muito mais comum, o lado inconsciente da história. Claro, que descobrimentos assim relativizam os valores predominantes na cultura ocidental - o mito prometeano do progresso - e os colocam no quadro mais largo.

\title{
3. O nacionalismo literário de Maurice Barrès: la terre et les morts
}

History is a series of images, tales, geographies, figures, lessons. It's not so much fact. [História é uma série de imagens, contos, geografias, figuras, lições. Não tanto os fatos]. (HILLMAN, 1983, p. 80)

\footnotetext{
7 Como historiador eu posso falar só por mim mesmo, mas na minha opinião, Jung acrescentou uma nova dimensão à história abrindo, para os historiadores, uma entrada através da qual eles podem explorar as profundezas subconscientes da psique. E ele, como eu acredito, faz mais para a história do que isso. O subconsciente é como o rio subterrâneo no qual fontes de todas as atividades conscientes extraem suas águas. $O$ subconsciente é uma avenida para o estudo compreensivo da natureza humana e dos assuntos humanos.

${ }^{8}$ Historiadores como Hunt, Barzun ou Stannard perguntaram porque o pensamento historiográfico da psicologia profunda, que compartilham tanto, não conseguiram fazer uma parceria de sucesso.
} 
l'idéologie, ne l'oublions pas, est l'interaction de la culture et de la politique [Não esqueçamos que a ideologia é a interação entre a cultura e a política]. (STERNHELL, SZNAJDER, ASHÉRI, 1989, p. 12)

Outrora, quando começou a desintegrar-se vivos os mitos cristãos que serviram como base da ordem social e política (o mito sobre a origem divina da realeza, sobre a terra posicionada no centro do universo colocada entre os céus e o inferno), foram substituídos pelos mitos seculares e racionalistas. As sociedades ocidentais rejeitavam o direito divino do poder real e das dinastias como ultrapassados e adotaram a tese sobre a soberania dos povos, o direito ao voto, o constitucionalismo, surgiram sistemas partidários etc. Em outras palavras, as instituições e a vida políticas foram secularizadas.

Mas, no fim do século XIX, o novo mito que emergiu da Revolução Francesa - e que atingiu também a América Latina - entrou na crise e foi essa crise que provocou a subida dos novos mitos políticos. Esses, frequentemente usavam o imaginário romântico, mas também os mitos seculares que consistiam em extensão da biologização das ciências sociais (darwinismo, darwinismo social, antisemitismo, degeneração, decadência). Em outras palavras, a Europa tornou-se mitologicamente dividida em mito universalista (a tradição iluminista saindo do liberalismo economico e político, jusnaturalismo e da teoria do contrato social) e em mito particularista (mito de uma ligação mística entre a alma nacional com os antepassados e terra cuja consequência é a que não existe nada como verdade histórica objetiva ou história universal, mas só particular). Enquanto a primeira tradição exigia um presidente e um governo eleito no processo das eleições gerais, a outra exigiu um leader, l'homme providentiel que asseguraria um laço forte com o passado do país ou a alma ancestral. Como nos lembra Zeev Sternhell:

En effet, la France produit à la fois une tradition politique rationaliste universaliste et humaniste mais aussi son antithèse organiciste particulariste reposant sur un relativisme doublé d' irrationalisme, qui dès la fin du XIXe siècle entre en révolte contre la démocratie, le liberalisme, le socialisme démocratique issu du marxisme et fidèle à son contenu rationaliste. Cette deuxième tradition politique exerce tout au long du XXe siècle une influence considérable sur l' évolution des mentalités [...] (STERNHELL, 2000: endpaper). ${ }^{9}$ ${ }^{9} \mathrm{Na}$ verdade a França produziu ao mesmo tempo uma tradição política racionalista, universalista e
humanista mas também a sua antítese organicista e particularista que consistiu no relativismo 
Falando sobre as duas tradições políticas, Sternhell fala na verdade dos dois imaginários nacionais que continuam vivendo e ficam repetidamente ativados na psicologia coletiva francesa. Se formos atentos, vamos enxergar aquele conflito político e cultural, que é, na verdade, um conflito arquetípico cujos porta-vozes se tornaram - principalmente nos períodos da crise alguns escritores. Agora vou voltar a minha atenção ao Maurice Barrès, às vezes chamado prince de la jeunesse.

Quando, no ano 1897, foi publicado o romance de Maurice Barrès, Les Déracinés, um dos casos mais exemplares do nacionalismo literário o qual faz o seu papel mais imaginário do que a teoria. Barrès reagiu à atmosfera da decadência a tornou-se um dos autores do diagnóstico psicológico da sociedade. Barrès não era autor das análises teóricas como encontramos em português Antero de Quental (Causas da decadência dos povos peninsulares, 1871) nem de criação ensaística, denunciando a sociedade, como no caso do espanhol Ángel Ganivet (Idearium Español, 1897) ou em brasileiro Paulo Prado (Retrato do Brasil, 1928). Também não se tratou da poesia anunciando o desaparecimento da nação (Guerra Junqueiro, Finis Patriae, 1890). As análises de Barrès foram baseadas no princípio de Hypolite Taine race, milieu, moment como os três fatores determinadores na evolução dos povos. A obra dele evoluiu 1) no contexto da passagem da inteligentsia francesa da esquerda a direita, 2) no contexto da assim chamada decadência, 3) no contexto da ascensão do anti-semitismo e no revanchismo. Estes três fatores - aos quais temos que acrescentar também o darwinismo social - determinaram completamente o imaginário criativo de Barrès. O que fica no âmago deste imaginário? É uma imagem de decadência, de morte e de degeneração da energia e das virtudes nacionais. Barrès falou de nihilisme moral ao qual acusava tudo que estivesse associado com o progresso: racionalismo, ciência, industrialismo, urbanismo, abandono do estilo de vida tradicional rural e prémoderno. Todas estas características tinham um denominador comum: a decadência. Antes de Barrès foram Hyppolite Taine, Lemaitre, Paul Bourget, Charles Baudelaire, Flaubert ou Huysmans que assumiram a mesma atitude. Muitos deles comparavam a decadência francesa e europeia com o Império

multiplicado pelo irracionalismo, que, a partir do fim do século XIX, entrou em revolta contra a democracia, o liberalismo, o socialismo democrático, que vinha do marxismo e foi fiel ao seu conteúdo racionalista. Esta segunda tradição política exerce uma influência considerável sobre a evolução das mentalidades durante todo o século XX. 
romano tardio. Para Théophile Gautier o exemplo ideal do crítico da modernidade Charles Baudelaire porque o seu

art arrivé à ce point de maturité extrême [...]. Ce style de décadence $[. .$.$] on peut rappeler, à propos de lui, la langue$ marbrée déjà des vendeurs de la décomposition et comme faisandée du Bas-Empire romain et les raffinements compliqués de l' école byzantine [...]. (STERNHELL, 1972, p. $40-41) \cdot{ }^{10}$

No ano 1885 Paul Bourget definiu decadência da seguinte maneira:

l' état d' une société qui produit un trop grand nombre $\mathrm{d}^{\prime}$ individus impropres aux travaux de la vie commune [...]. La société romaine produisait peu d' enfants: elle en arrivait à ne plus mettre sur pied de soldats nationaux [...] $\mathrm{L}^{\prime}$ entente savante du plaisir, le scepticisme délicat, $l^{\prime}$ énérvement des sensations, $l^{\prime}$ inconstance du dilettantisme, ont été les plaies sociales de l'Empire romain $[. .$.$] (STERNHELL, 1972, p. 41). { }^{11}$

No romance Déracinés Barrès descrevia a França como "dissociée et décérébrée" e como muitos outros autores, se aproveitava da metáfora que comparava a sociedade com o organismo, o indivíduo à célula. Esta metáfora tinha sua origem na noção romântica da nação de Herder. Tal compreensão da nação não admitiu o individualismo da tradição liberal e revolucionária e a base da sociedade viu em família, laços familiares, religião católica e tradições católicas:

Une société doit être assimilée à un organisme. Comme un organisme [...] elle se résout en une fédération $\mathrm{d}^{\prime}$ organismes moindres, qui se résolvent eux-mêmes en une fédération de cellules. L' individu est la cellule sociale. Pour que $\mathrm{l}^{\prime}$ organisme total fonctionne avec énergie, il est nécessaire que les organismes composants fonctionnent avec énergie [...] (BOURGET, 1885, p. 24-25) $)^{12}$

Esta tendência era patente não só na França. A repercussão foi visível também em outras partes da Europa. Barrès foi provávelmente o único

\footnotetext{
${ }^{10} \mathrm{~A}$ arte chegou a esse ponto de maturidade extrema [...] Este estilo de decadência [...] nos pode lembrar, quanto a ele, língua mármorea dos vendedores da decomposição e como faisandée do império romano tardio e a afinações complicadas da escola bizantina.

${ }^{11} \mathrm{O}$ estado de uma sociedade que produz um número grande demais de indivíduos inapropriados aos trabalhos da vida da comunidade [...]. A sociedade romana produziu poucos filhos: já não conseguiu ter os soldados nacionais [...]. O Acordo sábio do prazer, do ceticismo delicado, do l'énérvement das sensacoes, da inconstância do diletantismo, eram feridas sociais do Império Romano.

${ }^{12}$ A sociedade pode ser comparada a um organismo. Como o organismo [...] ela está dividida em federações dos organismos menores que são constituídos também pelas federações das células. 0 indivíduo é uma célula social. Porque o organismo total social funciona com energia, é necessário que os organismos parciais funcionem com energia.
} 
escritor que ligou literatura e política com tanta intensidade. Segundo o historiador Robert Soucy, o romance Déracinés fez com que a palavra "'deraciné' tornou-se a palavra chave do dicionário político francês. O culto barrèsiano la terre et les morts encontrou um público enorme na França (SOUCY, 1972, p. 50). Assim Barrès foi um escritor que também contribuiu com a passagem da inteligentsia francesa da esquerda para a direita:

Barrès played a major role in the Nationalist Revival that swept France between 1905 and 1914. Here, too, his influence was more that literary. Throughout most of the nineteenth century, nationalism in France had been associated with the Jacobin Left and the Paris Communard of 1871. It was now embraced by the antiJacobin Right as well. The famous call to fraternité of the French Revolution was now adopted by upper-class conservatives - the rest of the triad, liberté and egalité being courted less ardently. This shift in attitude [...] climaxed in the decade before the First World War (SOUCY, 1972, p. 9)..$^{13}$

Barrès desempanhava maior papel na renascença nacional que passou pela França nos anos 1905-1914. Também aqui, a influência dele era mais do que só literária. Durante a maior parte do século XIX o nacionalismo na França era associado com a esquerda jacobina e os communards de Paris de 1871.

A influência barrèsiana foi tão significativa que interferia na política estrangeira francesa da época:

Barrès is significant, too, because of his influence, albeit indirect, on French foreign policy between 1905 and 1914. His novels and frequent articles in the press during this period advocating a war of revenge against Germany (Barrès himself was a native of Lorraine) represented an important section of French opionion, especially in the capital (SOUCY, 1972, p. 11). ${ }^{14}$

\footnotetext{
${ }^{13}$ Barrès desempanhava maior papel na renascença nacional que passou pela França nos anos 19051914. Também aqui, a influência dele era mais do que só literária. Durante a maior parte do século XIX o nacionalismo na França era associado à esquerda jacobina e à communards de Paris de 1871. Agora foi adotado também pela direita anti-jacobina. A famosa chamada da Revolução Francesa para a fraternidade foi agora adotada pelos conservadores da classe alta - o resto da triade, liberdade e igualdade foi muito menos curtido. Essa mudança na atitude [...] culminou uma década antes da Grande Guerra.

${ }^{14}$ Barrès é significante também por causa da influência dele, mesmo que indireta, sobre a política francesa estrangeira nos anos 1905-1914. Seus romances e seus artigos na imprensa durante esse período defendendo a revanche contra a Alemanha (Barrès próprio nasceu na Lorena) representavam uma seção importante da opinião pública francesa, nomeadamente na capital.
} 
O imaginário de Barrès estava evoluindo. A obra dele pode ser dividida em dois períodos. O primeiro se caracteriza em individualismo egocentrico estreito que come Culte du moi patente no seu primeiro romance Sous l'oeil des barbares (1888) onde o eu frágil e fraco do héroi é compensado pelas atitudes extremamente fortes à não-eu (outras pessoas). No segundo período, o eu individual é substituído por "moi nacional" que luta contra "autre" bárbaro (outros povos, seus costumes e valores). É claro que Barrès trocou o moi egocentrico original pelo moi coletivo nacional. De qualquer modo, a "religão de enraizamento" apareceu só no segundo período. Esta virada de atitude já encontramos no romance Un homme libre (1889), onde o moi estreito do héroi, Philippe, torna-se, dos interesses pessoais dele aos interesses coletivos de Lorena e começa a cogitar a questão do enraizamento como possível solução da decadência:

Philippe begins to wonder whether the ancestral
traditions and the folk soul of Lorraine might not offer
his moi the nourishment it desires. [...] Undeterred,
Philippe returns to Lorraine in search of his identity. In
his moi, he asks, the product of Lorraine, of all its past
and present inhabitants? He does not readily answer yes.
He finds it difficult at first to identify with the culture
and people of Lorraine: they strike him as too banal, drab,
and joyless. His attitude changes, however, as he senses
that the soul of Lorraine does indeed live within him, that
it is the very essence of his being (SOUCY, 1972, p. 69-70). ${ }^{15}$

Nas obras de ambos os períodos podemos pressentir um conflito interior "moi-les autres", que acompanha toda a juventude dele. Já na família e na escola, Barrès vivenciava conflitos em vários níveis. Principalmente com a autoridade paternal, mais tarde com os colegas e com professores e ainda mais tarde vivenciou invasão prussa na Lorena. Assim, a revolta dele literária contra a decadência pode ser vista também como expressão do conflito interior dele próprio e como a tentativa de "resolver" a humilhação e a fraqueza outrora vivenciados. Seus hérois são frequtentemente jovens decadentes que tentam superar a própria fraqueza deles e assumem as atitudes heroicas e assim, pouco a pouco, ganham acesso a própria vitalidade

\footnotetext{
${ }^{15}$ Philippe começa a perguntar se as tradições ancestrais e a alma do povo de Lorena poderia oferecer para eu moi dele uma nutrição que ele deseja. [...] Sem medo, Philippe volta à Lorena procurando a sua identidade. No moi dele, ele pergunta pelo produto da Lorena, pelo passado e pelo presente dela e pela sua população. Ele não responde oui com prontidão. No início, ele acha difícil identificar-se com a cultura e o povo de Lorena: eles o surpreendem como povo banal, monótonos e sem alegria. Mas a atitude dele muda quando sente que a alma de Lorena realmente vive dentro dele e que é uma essência verdadeira dele também.
} 
e regeneração. Este tema é patente na trilogia dele Culte du Moi (romány Sous I' oeil des barbares, 1888, Un homme libre, 1889 e Le Jardin de Bérénice, 1891) cujo héroi

[...] is a young man consumed with decadence, weaker than the "barbarians" who surround him, alienated from the real world, divorced from all that is strong and vital in life. As a schoolboy, he resents the stronger boys who bully him - but at the same time he also envies them. In retreating from them into his moi, into his self, he also retreats from the real world that they represent - a rough, tough, Darwinian world. His goal throughout the trilogy is to overcome this decadence and regenerate his moi (SOUCY, 1972, p. 39-40) ${ }^{16}$

Barrès é o caso de um autor cujo trauma pessoal durante a vida projetou no nacionalismo literário par excellence e que exerceu uma influência enorme - da mesma maneira como Henri Bergson - não só em literatura francesa, na política estrangeira francesa mas também na juventude nas vésperas da Grande guerra. Isso se refere também à Pierre Drieu La Rochelle (1893-1945) cujo dilema se manifesta nos hérois de seus romances que são parecidos àqueles que encontramos nas personagens barrèsianas. Os heróis de Drieu, consumidos pela decadência, refletem à luta do próprio autor por vida vital e viril. Atrás da luta contra a decadência dos hérois de Drieu há um trauma pessoal, uma inveja e um ódio em relação àqueles que ele percebe como "mais fortes":

Je $\mathrm{m}^{\prime}$ écartais des bons élèves, des quelques garçons qui restaient paisibles, réguliers, sans inquiétude. I' étais attiré par les plus mauvais [...] C' était une complicité chaleureuse contre tout ce qui nous gênait ...Nous étions possédés par l' esprit de subversion. Nous méprisions et haïsions les gens âgés. Nous étions aveugles et violents. Nous ne songions qu'à l'émeute (DRIEU LA ROCHELLE, 1921, p. 13) $)^{17}$

\footnotetext{
${ }^{16}$ [...] é um homem jovem consumido pela decadência, mais fraco que os "bárbaros" que o rodeiam, alienado do mundo real, divorciado de tudo o que é forte e vital na vida. Como aluno ressente-se com os meninos mais fortes que praticam bulling contra ele - mas ao mesmo tempo ele os inveja. Refugiando deles no seu moi, ele se refugia também do mundo real que eles, os meninos, representam - mundo darwiniano bruto e duro. Durante toda a trilogia, o objetivo dele é superar esta decadência e regenerar o moi dele.

${ }^{17}$ Eu me afastava dos bons alunos, de certos meninos que qui restaient paisibles, réguliers, sans inquiétude. Eu era atraido aos piores [...] Foi uma cumplicidade calorosa contra tudo que os atrapalhava ...Fomos possuídos pelo espírito de subversão. Desdenhamos e odiamos as pessoas idosas. Fomos cegos e violentos. Sonhamos só com a rebeldia.
} 
Barrès teve contemporâneos numerosos que seguiram o mesmo caminho. Os mais conhecidos são Henry Montherlant, Alphonse de Chateaubriant, Louis-Ferdinand Céline, Pierre Drieu La Rochelle ou Robert Brasillach. Essa sua geração, desenvolveu o pensamento barrèsiano em culto do inconsciente, do irracionalismo e do instinto e assim a revolta contra o espírito iluminista veio ao seu apogeu:

\begin{abstract}
La vision du monde de Drieu La Rochelle, comme celle de Benn, de Hamsun et de Jünger, est dominé par la psychologie. Sans tomber dans l'excès de l'analyse psychologique, il a souvent recours à l'âme humaine, quand il veut comprendre et expliquer l'art, la philosophie, la politique. Sans être intuitionniste au sens bergsonien sur le comportement de l'homme: l'âme est conditionné par la physiologie; ce qui semble spirituel dans l'âme humaine n'est qu'une forme sublimée de la vie animale et instinctive (KUNNAS, 1972, p. 26-27). ${ }^{18}$
\end{abstract}

Mesmo que a interpretação psicológica ou psicanalítica não seja suficiente, porque a atmosfera decadente na sociedade francesa desempenhava também um papel importante, no nível mais profundo, inconsciente, e as gerações geralmente compartilham o mesmo imaginário coletivo. Assim, o processo criativo em uma geração vem sempre da interação do eu individual com as camadas inconscientes coletivamente compartilhadas, e o ambiente, frequentemente, faz papel de catalisador dos conteúdos inconscientes. No próximo capítulo, veremos o pensamento de um dos contemporâneos de Barrès, Charles Maurras.

\title{
4. "Imaginative-regressive leap":
}

\section{Charles Maurras e o paraíso mediterrâneo rural e latino}

A procura da identidade pessoal, a confrontação com as autoridades e o sentimento de fraqueza em relação à vida levaram Barrès não só ao esforço da autenticidade através da literatura, mas também à transferência dos conflitos interiores no mundo da política e da ideologia com uso da doutrina própria "la terre et les morts". Barrès apegou-se ao mundo dos

\footnotetext{
${ }^{18}$ A mundivisão de Drieu La Rochelle, com aquela que Benn, Hamsun e de Jünger, é dominada pela psicologia. Sem cair na análise psicológica excessiva, ele frequentemente recorre à alma humana quando quer compreender et expliquer arte, filosofia, política. Sem ser intuitivista no sentido bergsoniano sobre o comportamento humano: a alma é condicionada pela fisiologia; o que parece espiritual no sentido da alma humana é só uma forma sublime da vida animal e instintiva.
} 
ancestrais, o que poderia ser denominado de arquétipo maternal cuja expressao exterior era o lar, a pátria, a família, a nação. E é justamente esse complexo maternal que está no âmago dos ataques contra "barbares".

O contemporâneo de Barrès, Charles Maurras, talvez seja ainda um melhor exemplo de "deslocamento", de "projeção" a da "idealização" do mundo interior à realidade externa. Se Barrès idealizou os antepassados, as tradições, o passado e as virtudes nacionais, Maurras foi muito mais longe. Porque considera os franceses como os herdeiros de Grécia e de Roma e consequentemente - é o grande defensor do classicismo, constrói uma mitologia do mundo clássico que deve ser de novo incarnada não só na França, mas também nos outros países latinos, e parar o progresso da modernidade. Trata-se da fantasia regressiva que deve proteger Maurras contra o surto das forças alheias? Como escreve James Hall, as fantasias paradisíacas constituem o imaginário de um refúgio seguro sem conflito, sem obstáculos ou sofrimento, i.e., um ambiente materno protetor nutritivo:

pastoral paradise [...] inhabited by shepherds and shepherdesses, and nymphs and Satyrs, who dwell in the atmosphere of romantic love [...] The idealized rural retreat, the place of escape from the reality and complexity of life in town and court, if fundamental to the idea of Arcadia (HALL, 1979, p. 30) ${ }^{19}$

Como Barrès, Maurras era também político, ideólogo e teórico da arte. Em todas essas áreas está presente nao só o anti-modernismo dele ou "un mythe majeur du XIXe siécle français: la décadence" (Victor N' Guyen), mas nomeadamente a imagem da época clássica mítica na qual rege a ordem e a beleza. Neste sentido, Maurras se esforçou para obter uma harmonia entre a política, a arte e a alma ancestral (assim como mais tarde o nazismo ou o fascismo). Por exemplo, no ano 1891, junto com Jean Morèas, fundou L'École romane, cujas ambições e objetivos refletem no sonho latino de Maurras:

L'École Romane Française revendique le principe grécolatin, principe fondamental des Lettres francaises qui fleurit aux XIe, XIIe, XIIIe siècles avec nos trouvères; au XVIe avec Ronsard et son école; au XVIIe avec Racine et La Fontaine. [...] L'école romane francaise renoue la chaîne gallique, rompue par le Romantisme et sa

\footnotetext{
19 O paraíso pastoral [...] povoado pelos pastores e pastoras, e ninfas e sátiros que habitam numa atmosfera do amor romântico [...] O refúgio rural idealizado, o lugar de fuga da realidade e a complexidade da vida na cidade e na corte, é fundamental para a ideia da Arcádia.
} 
descendance parnassienne, naturaliste et symboliste [...] (RAYNAUD, 1939, p. 202). ${ }^{20}$

Também Maurras desejava o abraço ao passado, procurava segurança nas tradições nacionais, mas diferentemente de Barrès, o "outrobárbaro", essas foram para ele só culturas não-latinas e protestantes. Os ditadores nos países de línguas românicas (inclusive América Latina) não representavam nenhum perigo. Muito pelo contrário, elites brancas latinoamericanas apreciavam o pensamento maurrassiano: "il ne fallait confondre à aucun prix Hitler, ce vague produit de 1'anarchique forêt germaine, avec les magnifiques héros des renaissances du monde latin, un Salazar, un Franco, un Mussolini"(MÈGE, 2003: 25). ${ }^{21}$

Nascido em Provença, Maurras esforçou-se para o renascimento da França em todos os aspectos - politicamente (através do projeto da restauração da monarquia hereditária), esteticamente (no regresso ao classicismo e à arte clássica como arte estatal), religiosamente (no regresso a uma mescla do catolicismo e paganismo clássico), na área da política de trabalho (no corporativismo: regresso às corporações medievais) e também no campo da política internacional (estabelecimento da Union latine). No início quando era membro da Félibrige de Paris - quis mudança só na área da arte e da estética mas Affaire Dreyfus fez dele mesmo, como de Barrès, uma das maiores figuras do conservadorismo. Assim, Maurras logo tornou-se um líder da Action française, que tinha como objetivo principal derrubar a Terceira República e assim realizar todos os objetivos de Maurras.

Uma das visões centrais do pensamento de Maurras era a ideia de Latinité. Essa ideia não foi justificada pela experiência direta do autor com os outros povos e culturas deles, mas numa fantasia interior provavelmente muito realística atrás da qual ficou o medo do mundo anglo-protestante. A citação seguinte demonstra que a Latinité de Maurras tinha realmente proporções globais:

\footnotetext{
${ }^{20}$ L'École Romane retoma o princípio greco-latino, princípio fundamental das letras francesas que floresceu nos séculos XI, XII e XIII com os nossos trovadores; no século XVI com Ronsard e a escola dele; no século XVII com Racine e La Fontaine. [...] a Escola romana francesa religa a corrente gálica, que foi rompida pelo romantismo e por sua descendência parnassiana, naturalista e simbolista [...]. Jean Moréas, Lettre au Figaro citado em Ernest Raynaud no prefácio da obra dele Choix de poèmes publicado em Mercure de France, 1939, p. 202.

${ }^{21}$ No caso nenhum deveriamos confudir Hitler, este produto vago da florestas anárquicas germánicas com os hérois excelentes da renascença do mundo latino como Salazar, Franco, Mussolini.
} 
Ma Méditerrannée ne finit pas à Gibraltar, elle reçoit le Guadalquivir et le Tage, elle baigne Cadix, Lisbonne et s'étend, bleue et chaude, jusqu'à Rio de Janeiro. Elle atteint le Cap Horn, salue Montevideo, Buenos-Ayres et, sans oublier Valparaiso ni Callao [...]; elle court au SaintLaurent et, sauf de menues variations de couleur ou de température, va se jeter dans la baie d'Hudson où elle entend parler francais. Le caprice de cette Méditerranée idéale la ramène alors dans notre hémisphère, mais nin pas nécessairement pour revoir Baléares, Cyclades, Oran ou Alger, car ni Anvers, ni Gydnis ne lui apparaissent barbares: ma Méditerranée ne demande pas mieux que de devenir nordique ou baltique pourvu que'elle rencontre, ici ou là, les deux lucides flammes d'une civilisation catholique et d'un esprit latin (MAURRAS, 1963, 21-22). ${ }^{22}$

O mito neo-tradicionalista de Latinité teve as suas analogias no Iberismo, no Peninsularismo e no Hispanismo espanhol e português, mas diferentemente deles, teve realmente proporções globais e expandiu tanto à América Latina quanto ao Québec, à Espanha, à Portugal, à Bélgica, à Suiça, à Roménia e até entre as minorias católicas francesas na Inglaterra e na Nova Inglaterra. Philippe Mège sumarizou esse conceito da seguinte maneira:

Pour Maurras cet antigermanisme, lent à s'exprimer dans le domaine intellectuel, notamment philosophique, est pourtant une évidence vécue dès le plus jeune âge. Maurras a toujours regardé vers le Sud, embrassant le monde latin et tournant les dos à l'Allemagne. L'opposition entre la Germanie et la Latinité gouverna ainsi toute sa vie intellectuelle, littéraire, philosophique et politique. Le catholicisme de ses premières années, comme plus tard son paganismem son rejet de Luther, du protestantisme et de la Révolution, sa réaction contre le romantisme: tout est ordonné par cette opposition fondamentale et irréversible entre le monde latin et le germanisme (MËGE, 2003, p. 51). ${ }^{23}$

\footnotetext{
22 o meu Mediterâneo nao acaba em Gibraltar, mas recebe Guadalquivir e Tejo, banha Cadiz, Lisboa e se espelha, azul e frio, até Rio de Janeiro. Ele atinge Cabo Cap Horn, cumprimenta Montevideo, BuenosAires e devemos esquecer nem Valparaiso nem Callao [...]; ele corre ao rio de São Lourenço e, com exceção de poucas variações da cor e da temperatura, ele entra na bahía de Hudson onde ouve falar francês. O capricho deste ideal Mediterrâneo a leva então ao nosso hemisfério, mas não necessariamente para rever Baleares, Cíclades, Oran ou Alger porque nem Anvers nem parecem bárbaros: o meu Mediterrâneo não pede nada melhor do que tornar-se nórdico ou báltico só para ele encontrar aqui ou aí as duas chamas lúcidas duma civilização católica e dum espírito latino.

23 Para Maurras, este antigermanismo que se manifesta lentamente no domínio intelectual, nomeadamente filosófico, é mesmo assim evidentemente vivo desde a juventude dele. Maurras sempre olhou para o sul, abraçava o mundo latino e voltava as costas à Alemanha. A oposição entre Germânia e Latinidade assim rege toda vida intelectual, literária, filosófica e política dele. O catolicismo tanto dos primeiros anos quanto mais tarde o seu paganismo, sua rejeição a Lutero, ao protestantismo e à revolução, sua reação contra o romantismo: tudo isso é estabelecido por essa oposição fundamental e irreversível entre o mundo e o germanismo.
} 
Mas a expansão desse conceito não levou só a ideia de uma futura Union Latine, mas também à uma interpretação específica da história. Maurras foi convencido de que a decadência da Europa tem a ver com três R: reforma, revolução e romantismo. A Reforma associava com GermánicoLutero, para ele "le grand separateur de la Germanie et la latinité" porque perverteu a unidade medieval católica europeia. Todos os três $\mathrm{R}$ associavamse com o protestantismo norte-europeu. Para ele, o germanismo moderno (que associava-se com o imperialismo alemão do século XIX e mais tarde com Adolf Hitler cujo nazismo entendeu só como extensão desse imperialismo) foi "pas dissociable du germanisme de l'Antiquité ou du Moyen-Age catholique contre lequel il lançait déjà ses 'barbares assauts"'(não pode ser dissociado do germanismo da antiguidade ou da Meia Idade católica contra qual ele já inicou seus assaltos bárbaros) (MÈGE, 2003, p. 24).

Mesmo que o maurrassismo teve uma grande carga de paganismo, encontrava um apoio considerável nos dois hemisférios:

Hors de France, le maurrassisme fournit à des groupes d'intellectuels [...] un prestigieux modèle, qui permet d'obtenir une reconnaissance sur la scène locale [...] propose une conception unitaire et essentialiste de la nation fondée sur des permanences présentées comme naturelles et anciennes telles la famille, les traditions, une culture propre etc. Cette conception peut servir à légitimer la revendication d'autonomie [against] un État 'pluriethnique', libéral ou démocratique. Le Maurrassisme est, enfin, une référence qui a pu servir de levier, permettant [...] le passage d'une revendication régionaliste à une revendication nationaliste, car il fournit des arguments utiles pour légitimer la nouvelle définition du groupe en 'nation' (POMEYROLS, HAUSER, 2001, p. 7). ${ }^{24}$

Como no caso do Barrès, a criação e o pensamento de Maurras foi condicionado pela vida interior, pelas crises religiosas (Nuit de Tholonet, Nuit de $P a u)$ e fantasias dele. Já desde a sua adolescência Maurras foi quase totalmente surdo e assim era isolado do mundo. Depois de ficar surdo Maurras se apegou ao catolicismo, e pouco depois passou por uma crise

\footnotetext{
${ }^{24}$ Fora da França, o maurrassismo abastecia aos grupos de intelectuais [...] um modelo prestigioso que facilitava obter reconhecimento no cenário local [...] propunha uma concepção unitária e essencialista da nação fundada sobre as permanências que foram apresentadas como naturais e antigas como a família, as tradições, a cultura própria etc.. Uma concepção assim podia servir de legitimação a revendicação da autonomia contra um estado 'pluriétnico', liberal e democrático. E finalmente, o maurrassismo é uma referência que podia servir como um instrumento que permitia [...] uma passagem de uma pretenção regionalista à uma pretenção nacionalista que fornece argumentos úteis para legitimar uma definição nova do grupo na "nação".
} 
religiosa séria e pensou em suicídio. A veracidade da ligação íntima com a verdade interior pareceu confirmar a sua atividade na imprensa conservadora, atividade em Félibrige de Paris, envolvimento em Affaire Dreyfus, fundação $L$ 'Ecole romane ou liderança da Action française. Mas o mundo real rejeitava aceitar essas verdades: "Une des constantes de l'action de Maurras fut d'être condamné par les autorités qu'il disait défendre. Il fut condamné avec une telle régularité qu'on peut y déceler une des logiques profondes de ses actes: le Félibre en 1893, le Vatican en 1926, le Prétendant en 1937, la Nation en 1945"[Uma das coisas constantes da ação de Maurras era o fato que ele foi sempre rejeitado pelas autoridades que ele defendia. Ele foi condenado com tanta regularidade, que poderíamos revelar nisso uma das lógicas profundas da atuação dele: por Félibrige no ano 1893, pelo Vaticano em 1926, pelo pretendente ao trono no ano 1937, e pela nação no ano 1945] (GOYET, 2000, p. 211). ${ }^{25}$

Diferentemente de Barrès, Drieu e outros - frequentemente associados com o fascismo francês - Maurras não era fascinado pelas forças irracionais, instintivas. Instinto, sexualidade, atuação e pensamento compulsivo, sangue e raça fazem papel importante no pensamento dele. Maurras é tipo apolíneo, romanticamente olhando para trás, esforçando-se pela renascença das instituições e acreditando no regresso histórico. Mesmo lutando contra romantismo, ele é romântico. Mesmo querendo voltar ao catolicismo, ele mesmo é agnóstico. Maurras é um intelectual moderno que sonha romanticamente com o paraíso perdido da tradição, com a vida rural e com o mundo pre-moderno seguro e idealizado. Também, nesse caso, a fantasia precede a realidade. Psicologizar o pensamento assim não é difícil:

This homesickness or nostalgia is apparently related to something which need not exist in external reality. It is the longing for oneness with the mother in a state of problem-free containment, where total harmony, full accord, utter security and consolation reing supreme. Ultimately, it is a longing for the mother as the "containing world", as experienced in the best of circumstances in the so-called primal relationship, the initial link between mother. The perspective of depth psychology links ideas of Paradise, the Golden Age or the

\footnotetext{
${ }^{25}$ Nesse aspecto, Maurras constitui um paradoxo: inspirador de muitos no exterior, mas também no próprio país - mesmo capaz de liderar a Action française, ser poeta e escritor reconhecido, membro da Académie française, não conseguiu ganhar simpatias daqueles que o apoiavam.
} 
"intact world" with the pre-conscious state of infancy [...] (JACOBY, 2006, p. 7). ${ }^{26}$

Como também ainda veremos, a ação criativa do padre, do politico, do ideólogo, do escritor quebequense inspirou-se nas fantasias inconscientes nostálgicas que tentava traduzir para a realidade quotidiana.

\section{O nacionalismo católico: Lionel Groulx}

Lionel Groulx (1878-1967) é conhecido como padre, professor universitário, historiador, ideólogo, representante e editor da Action française de Montréal, mas também como autor de três romances. Como no caso dos autores acima mencionados, o imaginário dele teve origem nas camadas mais profundas da psique e se caracteriza por traços semelhantes: o mito sobre a origem comum, a filosofia providencialista sobre a missão da civilização francesa, latina e católica no Mundo Novo, a veneração da sociedade prémoderna, suas virtudes, rejeição da modernidade, industrialização etc. Não é nenhuma surpresa que Action française de Paris considerava o Canadá francófono como um exemplo digno a seguir:

Heureux pays! Vous avez une foi, une langue, un esprit de famille, une paysannerie, des moeurs ...Où n'irait une race humaine avec de tels atouts? Comparez la stabilité, la fecondité de vos foyers à l'instabilité, à la stérilité du foyer américain. Votre moralité à la criminalité des autres. Votre fidelité, votre unité réligieuse, à leur morcellement, au pullulement de leurs sectes et de leurs temples! Votre puissance et courageuse continuité ethnique et linguistique à cette mosaïque d'immigrants de tous lieux et de tous pays! Comparez vos champs, même vos forêts, à l'industrialisme dont vos voisins sont prisionniers [...]. Un seul élément paraît militer contre vous, c'est leur nombre. Mais l'armée du roi des rois comptait des centaines de milliers d'hommes, et les bataillons de Miltiade, de Thémistocle et de Léonidas ne faisaient qu'une poignée [...] (MAURRAS, 1934, p. 217). ${ }^{27}$

\footnotetext{
${ }^{26}$ Esta saudade ou nostalgia está evidentemente relacionada com alguma coisa que talvez não exista na realidade exterior. É uma saudade por uma união com a mãe, no estado de contentamento sem problemas, onde uma harmonia total, um acordo pleno rege a consolação. No final das contas, é uma saudade pela mãe como um "um mundo contentor" como vivenciado nas melhores circunstâncias no assim chamado relacionamento primário, o link inicial com a mãe. A perspectiva da psicologia profunda liga ideias de Paraíso, da Idade de ouro ou do "mundo indene" com o estado pré-consciente da infância.

${ }^{27}$ País feliz! Vocês têm uma fé, uma língua, um espírito da família, um campesinato, uma moral ...Aonde pode chegar a raça humana com triunfos assim? Comparem a estabilidade, a fecundidade dos seus lares com a esterilidade dos lares americanos. Comparem vossa moral com a criminalidade dos americanos. Vossa lealdade, vossa unidade religiosa com a desintegração deles, com a poluição das seitas e dos
} 
O Canadá francês tinha razões para recear a sua existência no futuro e Groulx - sem apelações explícitas da independência - tornou-se um dos principais defensores da cultura francófona e católica no Québec e fora dele. Groulx sublinhava que os franco-canadenses e franco-americanos tinham não só missão providencial, mas também como primeiros conquistadores tem direito de ocupar toda América do Norte: "Le petit peuple de 1760 possédait tous les élements d'une nationalité: il avait une patrie à lui, il avait l'unité religieuse, l'unité de la vraie foi, et, avec elle, l'équilibre social et la promesse de l'avenir" [o pequeno povo do ano 1760 possuiu todos os elementos de uma nacionalidade: tinha uma pátria, tinha uma unidade religiosa, unidade de uma fé verdadeira e com ela o equilíbrio social e a promessa do futuro] (GROULX, 1919, p. 293). Mas Groulx não era Maurras quebequense: não era positivista nem agnóstico, não pregava uma religião secular da Latinité. Ficou muito mais perto do pensamento contrarevolucionário de Joseph de Maistre e de Maurice Barrès. Com o pseudônimo Alonié des Lestres Groulx publicou um romance cuja temática é próxima daquela de Barrès: $L^{\prime}$ Appel de la race (1922) - que tornou-se bestseller - e mais tarde Les Rapaillages. Vieilles choses. Vieilles gens (1916) e Au Cap Blomidon (1932). A estrutura do romance L'Appel de la race é muito parecida com a dos romances de Barrès. Nao há hérois decadentes, mas pessoas quais - através dos laços familiares e carreiras ficam entre as duas culturas e sociedades e são confrontadas com dilemas sérios. A narrativa está situada na capital federal Ottawa na época da crise línguística, e o héroi principal Jules de Lantagnac, jurista e membro do parlamento federal, estreitamente ligado com os grupos anglófonos em Ottawa. Mesmo sabendo que a luta dos franco-ontarianos é uma luta justa, hesita em ajudá-los no parlamento. Nem a mulher dele, anglo-católica Maud Fletcher seria capaz de tolerá-lo. Assim, Lantagnac está confrontado com o "appel de la race", i.e., com o mesmo problema barrèsiano que encontramos em "la terre et les morts".

Mas, como diz Bock, "[...]L'Appel de la race found itself at the heart of two major debates that stirred up the French-Canadian literary and

templos deles! Vosso poder é uma continuidade étnica e linguística corajosa à cette mosaïque d'immigrants de tous lieux et de tous pays ! Comparem vossos campos, até as suas florestas com o industrialismo dos seus vizinhos dos quais eles são prisioneiros [...]. Único fator que pareceu contrariar voces foi o número deles. Mas o exército dos reis contava com centenas de milhares de homens e os batalhões de Milcíades, Temístocles e de Leónidas formaram só pugilo de homens [...]. 
intellectual world for several months"(BOCK, 2014, p.169). A crítica literária acusava Lantagnac, o personagem principal, não só do paganismo e do comportamento destrutivo no matrimónio, mas também da hostilidade contra os anglo-canadenses. Nessa época, Groulx já era publicamente bem conhecido: já no ano de 1915 tornou-se professor de história canadense na Université Laval de Montréal e começou a ensinar história de Québec e $L^{\prime}$ Histoire canadienne como cursos específicos. No ano 1920 tornou-se editor da $L^{\prime}$ Action française de Montréal e punha ênfase no renascimento e na manuntenção das tradições velhas referentes à Nouvelle France (extinta pelo Tratado de Utrecht, 1713). Numa coleção de curtos contos Les Rapaillages, venerou virtudes de comunidades franco-canadianas rurais. Aqui e também nas duas outras obras, na universidade, nos seus discursos continuava salientando que entre americanos, anglo-canadenses e franco-americanos, franco-canadenses existe uma incompatibilidade fundamental. Aqui, ele seguiu o princípio segundo o qual a tradição = transmissão como é presente também em Maurras (mas no caso dele se trata de um princípio que justifica a monarquia hereditária). Em Groulx o "gênio" nacional foi uma expressão da alma ancestral, mas só se o povo mantivesse as tradições ancestrais. Só assim, segundo Groulx, o povo quebequense conseguiria manter a sua integridade e não desapareceria.

Groulx constitui uma prova de que o pensamento típico para a segunda parte do século XIX e primeira metade do século XX existiu também depois da Segunda Guerra Mundial. Se na Europa este pensamento era conservado, e existia só nos regimes da Península ibérica e nos grupos da extrema direita, nas Américas (nomeadamente na América Latina) era comum. O pensamento de Groulx teve sua influência mais forte nos anos $20 \mathrm{e}$ 30, mas depois a influência dele ficou mais fraca. Não foi assim nem por causa da guerra, da condenação papal de Maurras na França nem por causa da condenação de Maurras depois da guerra. No Québec apareceu uma leitura mais objetiva e moderna da história do Québec para a qual nem a alma ancestral nem a raça ou a missão providencial fazia papel importante :

Historians of French Canada generally consider the postwar years as a period of extraordinary transformation. Impelled by the young intellectuals of the 1940 s and 1950s, the nationalist movement sought to 'modernize' the French-Canadian nation. [...] On a great many questions, breaks with Lionel Groulx's thought 
were apparent. A significant portion of his intellectual heritage was rejected (BOCK, 2014, p. 211). ${ }^{28}$

Depois da Guerra, as ciências socias canadenses rejeitaram a leitura tradicioanalista da história e também o nacionalismo tradicionalista do governo provinciano quebequense de Maurice Duplessis. Na época, surgiram dois movimentos: o "neo-liberal" e o "neo-nacionalista". O novo pensamento rejeitou o princípio da providência divina, da raça e da alma ancestral. Os neoliberais (revista Cité libre fundada no ano 1950 por Pierre Elliott Troudeau e Gérard Pelletier e École des sciences sociales na Universíté de Laval) e neonacionalistas (historiador Maurice Séguin e a sua nova interpretaçã de Conquest do ano 1760) levaram à secularização e à desacralização do milieu intellectual e académico no Québec dos anos de 1950. Este processo teve sua continuação na forma de Révolution tranquile durante os anos de 1960 e nomeadamente na escola historioráfica École de Montréal (Michel Brunet), mas isso já foram os últimos anos de vida de Groulx.

\section{Conclusão}

Este artigo foi centralizado em Clio e Psique nas obras de alguns intelectuais francófonos. Todos eles escreviam romances e contos, mas ao mesmo tempo exerceram pápeis cruciais na política da época deles. Por um lado, suas obras literárias e ideológicas os mantinham em contato com o mundo íntimo do imaginário deles e, por outro lado, o envolvimento deles com a vida pública os convidava para a aplicação desse imaginário no mundo profano. Barrès foi extraordinariamente popular entre os franceses na época e a popularidade dele foi acentuada até fora da França. Maurras não tinha influência tão forte no povo (nomeadamente depois de 1926), mas entre os intelectuais de vários países e culturas (T. S. Eliot, Paul Claudel, Gilberto Freyre, Paulo Prado, António Sardinha, Jackson de Figueiredo, Alceu Amoroso Lima etc.) tinha uma influencia considerável, Drieu La Rochelle foi influente nomeadamente entre os filo-fascistas da direita francesa mas também além das fronteiras francesas (seu romance Gilles) e Lionel Groulx influenciou de

\footnotetext{
${ }^{28}$ Os historiadores da Canadá francesa geralmente consideram os anos do pós-guerra como período da transformação extraordinária. Instigados pelos intelectuais jovens dos anos 40 e 50 , o movimento nacionalista tentava 'modernizar' a nação franco-canadense. [...] Em muitas das grandes questões as rupturas com o pensamento de Lionel Groulx foram visíveis. Uma parte significativa da herança intelectual dele foi rejeitada.
} 
maneira importantíssima, pelo menos, 50 anos da história de Québec. Em todos esses autores, a realidade imaginada encontrava-se com a realidade e foi mais forte do que ela - e em nenhum desses casos, o sonho da transformação da sociedade foi realizado.

Tanto a psicanálise quanto a filosofia reconhecem a imaginação humana não como um processo de reprodução ou da imitação (de um original da ordem metafísica ou de um sistema universal de referências) mas como um processo autônomo e criativo. Também, como já foi mencionado, se sabe que enquanto uma grande parte do nosso imaginário inconsciente é compartilhada dentro de uma cultura, outra parte é compartilhada através das culturas. Os autores aqui mencionados foram defensores da assim chamada ordem nacional e as imagens utilizadas por eles tanto nas obras teóricas quanto nas literárias foram imagens referentes às raízes, às tradições, à raça, ao passado. O discurso deles manifesta um imaginário saudosista de um mundo pre-moderno, e se pregam regeneração, o fazem em nome do passado, em nome da retour à la terre. No fim do século XIX um discurso assim foi ainda possível, mas - como prova por exemplo o discípulo de Charles Maurras, Henri Massis - depois da Segunda Guerra Mundial, tornou-se anacrônico porque peuple no sentido tradicional, i.e. vivendo no campo, ligado à terra, já nao existia, ficou extinto:

Quand on dit le peuple, aujourd' hui, on fait de la literature, et meme une politique, parlementaire. Il n' y a plus peuple. Tout le monde est bourgeois ...Le peu qui restait de $l^{\prime}$ ancienne ou plutôt des anciennes aristocraties est devenu une basse bourgeoisie. $\mathrm{L}^{\prime}$ ancienne aristocratie est devenu comme les autres une bourgeoisie de l' argent. Quant aux ouvriers, ils $\mathrm{n}^{\prime}$ ont plus qu' une idée, $\mathrm{c}^{\prime}$ est de devenir des bourgeois (MASSIS, 1943:52-5). ${ }^{29}$

\section{Referências}

ADAMS, Vannoy Michael. Fantasy Principle, Psychoanalysis of the Imagination, New York: Brunner-Routledge, 2004.

ADAMS, Vannoy Michael. The Mythological Unconscious, New York: Spring, 2010.

\footnotetext{
${ }^{29}$ Quando se fala do povo, fazemos literatura e até política parlamentar. O povo já nao existe. Todos são burgueses... o pouco que sobrou da aristocracia ou das aristocracias antigas tornou-se burguesia baixa. A aristocracia antiga tornou-se como os outros uma burguesia de dinheiro. Quanto aos operários, eles pensam numa coisa só - tornarem-se burgueses.
}

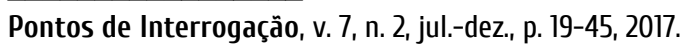


BOCK, Michel. A Nation Beyond Borders. Lionel Groulx on French-Canadian Minorities, Ottawa: University of Ottawa Press, 2014.

BOURGET, Paul. Essais de psychologie contemporaine, Paris: Lemerre, 1885.

COLLINGWOOD, R. G. The Idea of History, with Lectures 1926-1928, rev.ed. Oxford, UK: Oxford University Press, 1994.

DRIEU LA ROCHELLE. Pierre. L'État civile, Paris: Gallimard, 1921.

GOYET, Bruno. Charles Maurras, Paris: Presses de Sciences Po. Paris 2000.

GROULX, Lionel. Naissance d'une race. Montréal: L'Action française 1919.

HALL, James. Dictionary of Subjects and Symbols in Art, New York: Harper and Row, 1979.

HILLMAN, James. Inter-Views. Conversations with Laura Pozzo on Psychotherapy, Biography, Love, Soul, Dreams, Work, Imagination, and the State of Culture, New York: Colophon Books, 1983.

JACOBY, Mario. Longing for Paradise. Psychological Perspectives on an Archetype, Toronto: Inner City Books, 2006.

KUGLER, Paul. "Psychic Imaging: a bridge between subject and object", in: Young-Eisendrath, Polly-Dawson, Terence (Org.) The Cambridge Companion to Jung, Cambridge: Cambridge University Press, 2008.

KUNNAS, Tarmo. Drieu La Rochelle, Céline, Brasillach et la tentation fasciste, Paris: Les Sept Couleurs 1972.

LAQUEUR, Walter - MOSSE, George. L. Literature and Politics in the Twentieth Century, New York: Harper Torchbooks, 1967.

MAURRAS, Charles. "Dictionnaire politique et critique", In: L'Action française, August 30, 1934.

MAURRAS, Charles. Soliloque du Prisonnier, Paris: La France Latine, 1963.

MASSIS, Henri. Les Idées restent, Lyon: Lardanchet, 1941.

MEYER, Ruth. Clio's Circle. Entering the Imaginal World of Historians. New Orleans: Spring Journal Books, 2007.

$\mathrm{N}^{\prime}$ GUYEN, Victor. Aux origins de l'Action française. Intelligence et politique à l'aube du Xxe siècle, Paris : Fayard, 1991. 
POMEYROLS, Catherine - HAUSER, Claude (eds.). L'Action française et l'étranger. Usages, réseaux et répresentations de la droite nationaliste française, Paris: L'Harmattan 2001.

RAYNAUD, Ernest. Choix de poèmes, Paris: Mercure de France, 1939.

SOUCY, Robert. Fascism in France. The Case of Maurice Barrès, California: California University Press 1972

STERNHELL, Zeev. Ni droite ni gauche. La France entre nationalisme et fascisme, L' idéologie fasciste en France, Paris: Fayard, 2000.

STERNHELL, Zeev. Maurice Barrès et le nationalisme français, Paris: Armand Collin, 1972.

STERNHELL, Z. - SZNAJDER, M. - ASHÉRI, M.: Naissance de l'idéologie fasciste, Paris: Fayard, 1989.

TOYNBEE, Arnold J. “The Value of C. G. Jung's Work for Historians”, Journal of Analytical Psychology 1 (1956): 193.

Recebido em: 31/10/2017

Aprovado em: 04/12/2017 